\title{
Membrana amniótica na reconstrução da superfície ocular após exérese de carcinoma de células escamosas da conjuntiva
}

\author{
Amniotic membrane for ocular surface reconstruction after conjunctival \\ squamous cell carcinoma resection
}

\author{
PauloRobertodeCarvalho-Rêgo ${ }^{1}$ \\ José Álvaro Pereira Gomes ${ }^{2}$ \\ Priscila Luppi Ballalai ${ }^{3}$ \\ Marcelo Carvalho Cunha ${ }^{4}$ \\ Luciene Barbosa de Sousa ${ }^{5}$ \\ Clélia Maria Erwenne ${ }^{6}$
}

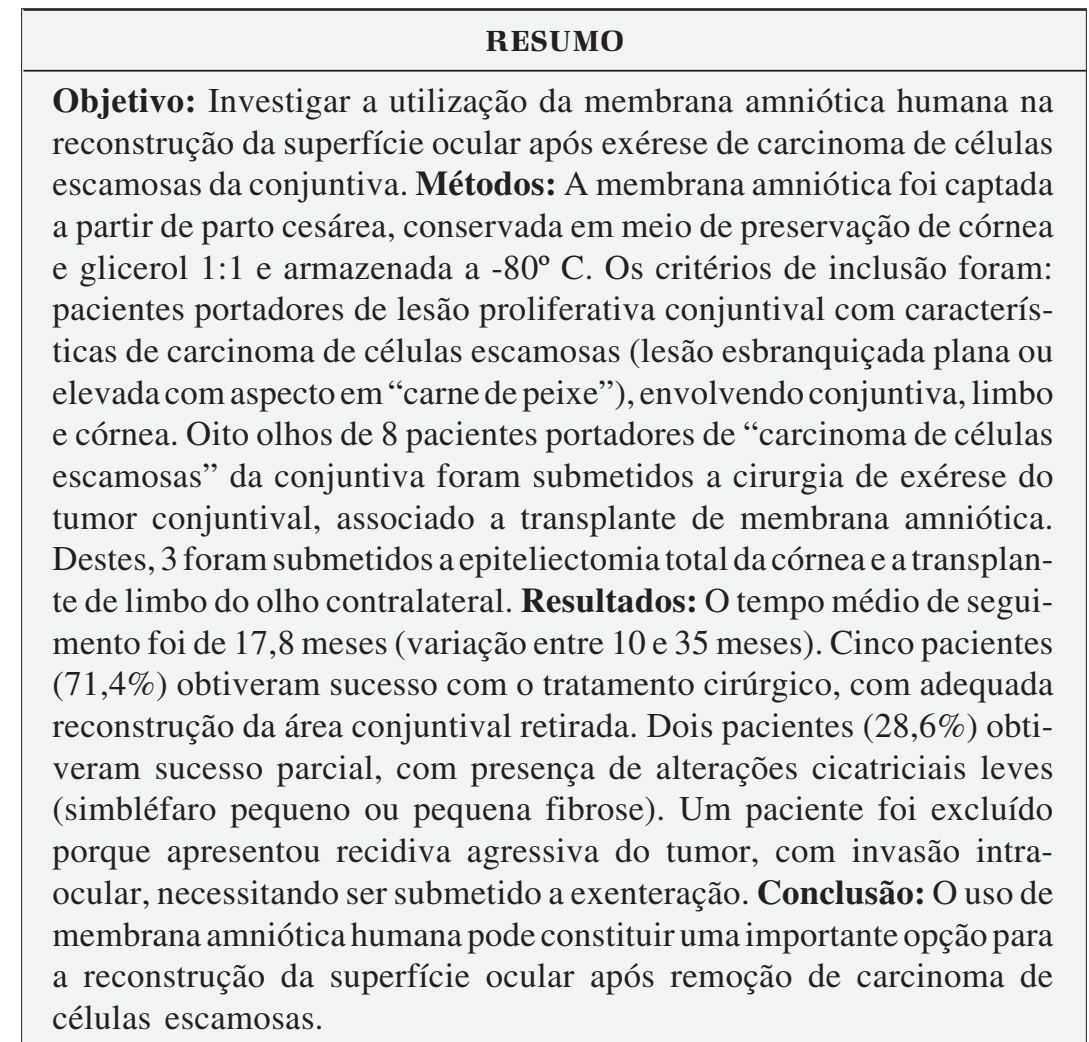

Descritores: Neoplasias da conjuntiva/cirurgia; Carcinoma de células escamosas; Âmnio/ transplante; Conjuntiva/transplante

\section{INTRODUÇÃO}

Os tumores conjuntivais podem ser divididos em pigmentados ou não pigmentados. Entre os não pigmentados, destaca-se o carcinoma de células escamosas (CEC), que é o tumor maligno conjuntival mais comum e tem maior incidência em indivíduos com maior exposição ao sol e mais idosos. O CEC pode ser dividido em "neoplasia intraepitelial conjuntival" (NIC) (quando ainda não ultrapassou a membrana basal da conjuntiva) e "carcinoma escamoso invasivo" (quando já ultrapassou a membrana basal). O tratamento classicamente preconizado é a excisão precoce do CEC, associada a crioterapia. Em casos avançados, pode ser necessário enucleação ou exenteração ${ }^{(1)}$. 
Cirurgias com retirada de extensa área de conjuntiva bulbar ou palpebral podem induzir alterações cicatriciais, muitas vezes com aparência desfigurante e restrição da motilidade ocular. Enxerto autólogo de conjuntiva (do mesmo olho ou do olho contralateral) ou de mucosa oral recompõe a região de onde foi retirada a conjuntiva ${ }^{(2)}$, mas pode levar a alterações cicatriciais na região doadora do enxerto ${ }^{(3)}$. Uma alternativa para a reconstrução da superfície ocular nesses casos de retirada extensa de conjuntiva é o uso de enxerto de membrana amniótica, que tem sido utilizado nas cirurgias de reconstrução da superfície ocular nos casos de doenças cicatriciais da córnea e conjuntiva, tais como queimadura, penfigóide cicatricial, eritema multiforme ${ }^{(4-6)}$; na promoção da cicatrização nos defeitos epiteliais persistentes ${ }^{(7)}$; como enxerto após a remoção cirúrgica de pterígio e tumores ${ }^{(3,8)}$; no tratamento de bolhas filtrantes com vazamento ${ }^{(3,9)}$; redução da opacidade corneal pós ceratectomia fototerapêutica ${ }^{(10)}$ e nas reconstruções palpebrais ${ }^{(3)}$.

A utilização de membrana amniótica como enxerto baseia-se nas suas características de não induzir rejeição por ser imunologicamente inerte (não apresenta antígenos de histocompatibilidade HLA-A, B ou DR), reduzir os processos inflamatório, angiogênico e cicatricial e beneficiar o processo de epitelização ${ }^{(11)}$.

O objetivo deste trabalho é avaliar a utilização da membrana amniótica na reconstrução da superfície ocular após exérese de carcinoma de células escamosas da conjuntiva.

\section{MÉTODOS}

\section{Obtenção e preparação da membrana amniótica}

A obtenção, preparação e preservação da membrana amniótica foram realizadas de acordo com as normas do protocolo aprovado pela Comissão de Ética da UNIFESP/EPM. Essas normas foram baseadas no protocolo proposto por Tseng et al. ${ }^{(5,12)}$, seguindo as premissas impostas pela "United States Food and Drug Administration (FDA)" e "The American Association of Tissue Banking (AATB)"(13-15).

A membrana amniótica foi obtida a partir de placentas provenientes de cesáreas eletivas de pacientes do Departamento de Obstetrícia e Ginecologia da UNIFESP e do Hospital e Maternidade São Luís, após consentimento assinado pelas gestantes. Todas essas pacientes tinham exames sorológicos negativos para HIV, Hepatite B e C e sífilis (VDRL), que foram reconfirmados pela realização de sorologia do sangue do cordão umbilical após o parto.

Após a obtenção da placenta no centro cirúrgico obstétrico, procedeu-se a sua lavagem com soro fisiológico $0,9 \% \mathrm{em}$ ambiente estéril. Utilizando-se tesoura e pinça estéreis, separou-se o âmnio do córion, estendendo-o sobre um filtro de nitrocelulose estéril (Millipore, Bedfort, MA, EUA) com a face epitelial para cima. A membrana amniótica e o filtro foram lavados com solução tampão fosfato contendo $1000 \mathrm{U} / \mathrm{ml}$ de penicilina, $20 \mathrm{mcg} / \mathrm{ml}$ de estreptomicina e $2,5 \mathrm{mcg} / \mathrm{ml} \mathrm{de}$ anfotericina $\mathrm{B}$, cortados em fragmentos de aproximadamente $3 \times 3 \mathrm{~cm}$, colocados em um recipiente estéril contendo glicerol (Baxter Healthcare Corporation, Stone Mountain, GA, EUA) e meio de preservação de córnea (Ophthalmos, São Paulo/SP, Brasil) na proporção de $1: 1$ e congelados a $-80^{\circ} \mathrm{C}$. Amostras de cada membrana obtida foram enviadas para estudo anátomo-patológico e microbiológico (bacterioscopia e cultura) para controle de qualidade. O tempo máximo para utilização das membranas foi de 4 meses após a congelação.

\section{Pacientes}

Os critérios de inclusão foram: pacientes portadores de lesão proliferativa conjuntival com características de CEC (lesão esbranquiçada plana ou elevada com aspecto em "carne de peixe"), envolvendo conjuntiva, limbo e córnea, diagnosticados clinicamente pelo Setor de Tumores do Departamento de Oftalmologia da UNIFESP e que tiveram comprovação anátomo-patológica.

O grupo envolvido no estudo foi de 8 pacientes ( 8 olhos) consecutivos portadores de CEC. Quatro pacientes $(50 \%)$ eram do sexo masculino e $4(50 \%)$ do feminino. A idade média era 66,6 anos (variação entre 24 e 83 anos). Todos os pacientes foram submetidos a exérese do tumor associado a crioterapia intra-operatória e enxerto de membrana amniótica. Três pacientes portadores de CEC com amplo ou total acometimento límbico foram, também, submetidos a transplante de limbo autólogo. Os detalhes e características dos pacientes e das condutas estão na tabela 1 .

\section{Pré-operatório}

Os pacientes foram submetidos a exame oftalmológico completo, incluindo biomicroscopia com e sem fluoresceína, tonometria de aplanação, fundoscopia e biomicroscopia ultrasônica. Também foi realizada análise citológica por citologia de impressão e exfoliativa. Foram feitas fotografias e realizado desenho no pré-operatório, com auxílio da lâmpada de fenda. A área do tumor foi calculada pela multiplicação dos maiores diâmetros horizontal e vertical observados na biomicroscopia e registrados no desenho.

\section{Técnica cirúrgica e pós-operatório}

Utilizou-se anestesia peri-bulbar com bupivacaína $0,75 \%$ (5 ml) e xilocaína $2 \%(2 \mathrm{ml})$ em todos os casos e a técnica cirúrgica utilizada foi a descrita na referência $\mathrm{n}^{\circ} 1$.

Para a remoção dos tumores que envolviam conjuntiva, limbo e córnea, foi realizado primeiramente epiteliectomia corneal com álcool absoluto. O desenho pré-operatório foi importante para ajudar a delimitar o acometimento corneal. Aplicou-se haste com algodão na ponta (Cotonete ${ }^{\circledR}$, Johnson \& Johnson, Brasil) ou esponja embebidos em álcool absoluto por 60 segundos nos epitélios corneal, límbico e conjuntival acometidos, deixando margem mínima de $2 \mathrm{~mm}$ de epitélio macroscopicamente saudável. Em seguida, com lâmina de bisturi $\mathrm{n}^{\circ} 15$, a partir de $2 \mathrm{~mm}$ da 


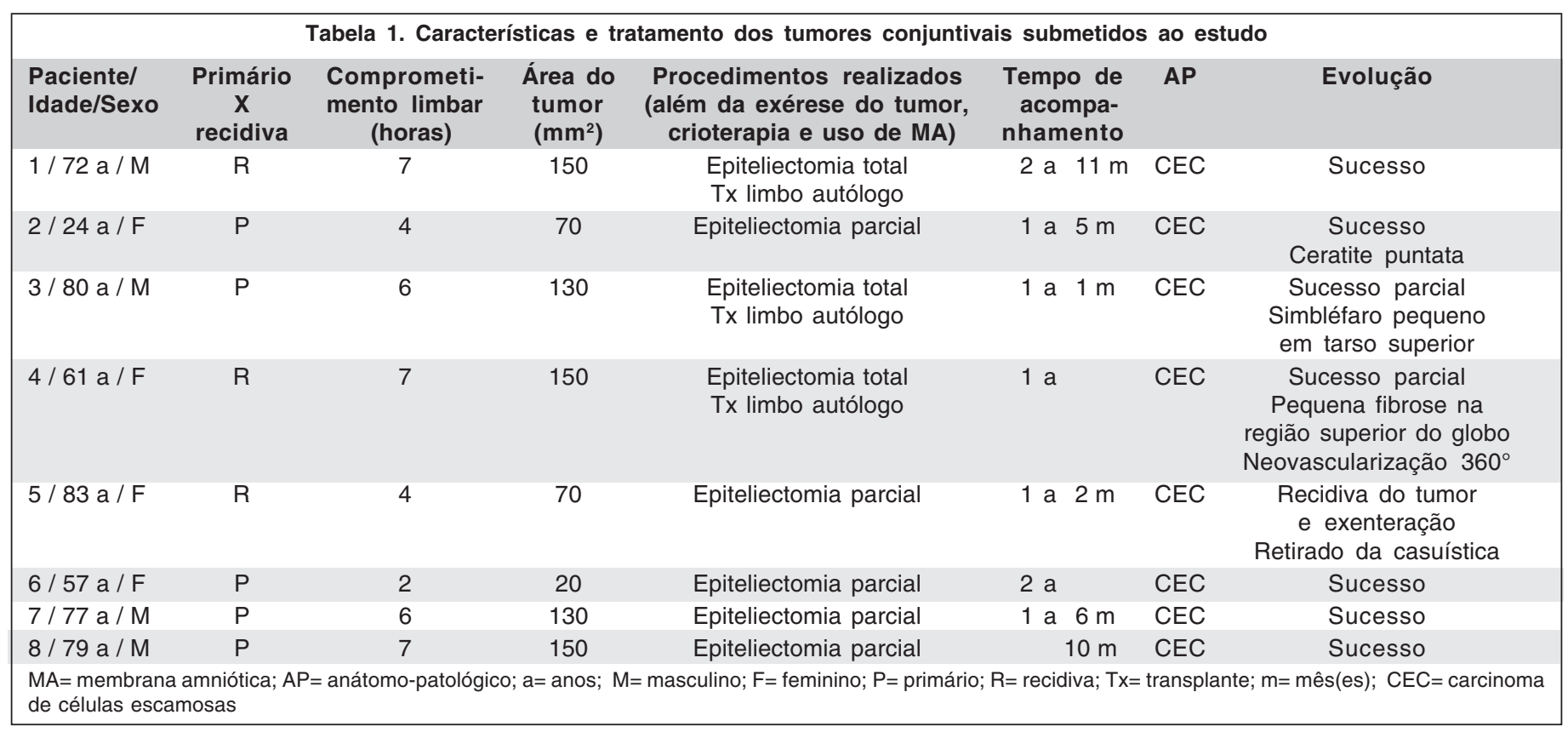

borda do tumor na córnea, retirou-se o epitélio até a camada de Bowman. Epiteliectomia total foi necessária nos casos avançados (casos 1, 3 e 4). A segunda etapa constou de remoção da porção conjuntival do tumor através de uma escleroconjuntivectomia lamelar. Levantou-se com uma pinça a conjuntiva da região límbica, 4 a $5 \mathrm{~mm}$ de distância do tumor, e fez-se incisão na conjuntiva com tesoura de Westcott (o processo foi repetido no lado oposto do tumor). Realizou-se ressecção da conjuntiva e cápsula de Tenon ao redor do tumor mantendo-se margem livre de 4 a $5 \mathrm{~mm}$, expondo-se a esclera, onde foi feita uma incisão a $2 \mathrm{~mm}$ da borda do tumor e um "flap" escleral fino foi confeccionado na direção do limbo por baixo do tumor até a camada de Bowman na córnea. Usou-se cautério bipolar para cauterização de vasos sangrantes e evitou-se o uso de esponja no tumor para não espalhar células tumorais. Usou-se álcool absoluto no leito escleral para desvitalizar qualquer célula tumoral residual. O tumor e o material proveniente da epiteliectomia foram enviados para exame anátomopatológico. A partir desse momento, novo material cirúrgico passou a ser usado para evitar contaminação por células tumorais nos tecidos adjacentes. Crioterapia em congelamento duplo foi executada em toda a margem da conjuntiva bulbar por 10 a 20 segundos.

A próxima etapa constou da reconstrução da superfície ocular. Utilizou-se enxerto de membrana amniótica para fechar o defeito conjuntival e corneal e, nos casos em que a ressecção do limbo foi de $360^{\circ}$, realizou-se enxerto de limbo autólogo (casos 1, 3 e 4). Após ser descongelada, a membrana amniótica foi lavada com solução salina balanceada por 5 minutos e colocada sobre o olho, mantendo a orientação da face da membrana basal (face epitelial) para cima. Nos 3 pacientes portadores de CEC com amplo ou total acometimento límbico (casos 1, 3 e 4), foi colocado membrana amniótica sobre toda a superfície da córnea e esta membrana foi suturada com pontos contínuos episclerais e na borda da conjuntiva restante com nylon 9-0. Foi retirado um fragmento de $8 \times 5 \mathrm{~mm}$ do limbo e conjuntiva superior-nasal do olho contralateral, que foi dividido em duas partes iguais. Esses dois fragmentos de limbo/conjuntiva foram suturados superior e inferiormente no limbo com quatro pontos separados de nylon 10-0 fixados na membrana/episclera. Nos outros pacientes, como o acometimento límbico era menor, foi realizado epiteliectomia parcial com retirada parcial do limbo e colocado membrana sobre o defeito córneo-conjuntival, suturando-a na episclera e na borda da conjuntiva com sutura contínua de nylon 9-0 e, quando necessário, na córnea com nylon 10-0.

No pós-operatório, foram instilados colírios de acetato de prednisolona $1 \%$ de $4 / 4$ horas nas primeiras duas semanas, com regressão progressiva e de ofloxacino $0,3 \%$ de $4 / 4$ horas apenas na primeira semana.

Os pacientes foram acompanhados no pós-operatório de $1^{\circ}$ e $3^{\circ}$ dias, $1^{\underline{a}}, 2^{\underline{a}}, 3^{\underline{a}}$ e $4^{\underline{a}}$ semanas, 1,5 mês, 2 meses, 2,5 meses, 3 meses e, a partir de então, mensalmente.

\section{Critérios de avaliação dos resultados}

Sucesso foi definido como uma adequada reconstrução da área conjuntival retirada (sem formação de simbléfaro, apenas com cicatrização na interface entre a membrana amniótica e a conjuntiva).

Sucesso parcial foi definido como presença de alterações cicatriciais leves (pequeno simbléfaro) ou pequena fibrose.

Insucesso foi definido como presença de alterações cicatriciais graves (simbléfaro ou fibrose excessivos). 


\section{RESULTADOS}

O tempo médio de acompanhamento dos pacientes foi de 17,8 meses (variação entre 10 e 35 meses).

A membrana amniótica incorporou-se ao leito receptor em todos os casos. A epitelização corneal ocorreu em um período máximo de 2 semanas naqueles pacientes em que foi realizado ceratectomia parcial (pacientes 2, 5, 6, 7, 8) e de 3 semanas naqueles submetidos a ceratectomia total (com retirada total do limbo) e transplante de limbo autólogo (pacientes 1, 3 e 4). A epitelização conjuntival também ocorreu entre 2 e 3 semanas em todos os casos. A membrana amniótica, por ser um tecido relativamente transparente, facilitou o exame sob a lâmpada de fenda nas avaliações pós-operatórias.

O paciente 5 , apesar de ter obtido uma boa reconstrução da superfície ocular nos primeiros dias de pós-operatório, apresentou recidiva do tumor, percebida no $20^{\circ}$ dia após a cirurgia, com quatro nódulos esclerais (dois inferiores, um superior e um nasal) e invasão intra-ocular. A lesão tumoral submetida à cirurgia era extensa, ocupando todo o fundo de saco e conjuntiva bulbar inferior e nasal e já era uma recidiva de 10 dias de uma lesão inicial operada em outro Serviço, ou então uma disseminação da lesão primária que não tivesse sido totalmente retirada. Esse paciente evoluiu para exenteração devido à recidiva, não podendo ser classificado como sucesso, sucesso parcial, nem insucesso, pois não foi possível um acompanhamento do caso.

Cinco pacientes $(71,4 \%)$ obtiveram sucesso com o tratamento cirúrgico com reconstrução conjuntival satisfatória (pacientes 1, 2, 6, 7 e 8) (Figuras 1A e B). É importante ressaltar que o paciente 2 , que era portador de xeroderma pigmentoso, teve o tumor removido e uma boa reconstrução conjuntival, mas evoluiu com epiteliopatia corneal crônica e necessitou de tarsorrafia adicional.

Dois pacientes $(28,6 \%)$ obtiveram sucesso parcial (pacientes 3 e 4). O paciente 3 evoluiu com formação de pequeno simbléfaro entre tarso superior e região temporal superior do globo ocular e o paciente 4 apresentou pequena fibrose na região superior do globo ocular.

Não houve pacientes com insucesso, ou seja, com alterações cicatriciais graves (simbléfaro ou fibrose excessivos). Também, observou-se no pós-operatório menor quemose e inflamação em relação ao que geralmente ocorre após a utilização da crioterapia sem transplante de membrana amniótica, gerando maior conforto ao paciente.

\section{DISCUSS $\tilde{A} O$}

A exérese de lesão tumoral conjuntival extensa cria uma área desepitelizada, que induz processo cicatricial, podendo vir acompanhado de simbléfaro, restrição da motilidade e aparência desfigurante nesta região ${ }^{(3)}$. Para evitar essas complicações, é importante que essa área seja recoberta adequadamente por tecido mucoso. Quando a área não é muito extensa, pode-se recorrer ao fechamento primário, mobilizando a conjuntiva vizinha após peritomia ou "deslizando" um retalho conjuntival ${ }^{(3)}$. Quando a área é mais extensa, utiliza-se enxerto autólogo de conjuntiva do olho contralateral ou de mucosa oral ${ }^{(2-3)}$. No entanto, esses tipos de enxerto podem acarretar alterações cicatriciais na região doadora, com as conseqüências já descritas. Nesse sentido, o transplante de membrana amniótica oferece vantagem sobre os outros tipos de enxerto mucoso, pois não induz alterações cicatriciais no doador e cria, no receptor, superfície propícia para proliferação de células com fenótipo de epitélio conjuntival normal, demonstrado por estudos empregando citologia de impressão ${ }^{(16-17)}$.

Outra vantagem da utilização do enxerto de membrana amniótica ao invés de mucosa labial é a transparência que a primeira possui, o que permite o exame de estruturas mais profundas no pós-operatório, podendo-se detectar mais precocemente alguma recidiva que possa ocorrer sob o tecido enxertado.

Experiências in vitro mostraram que a matriz estromal da membrana amniótica suprime a atividade do fator de crescimento beta (TGF- $\beta$ ) e a diferenciação miofibroblástica de
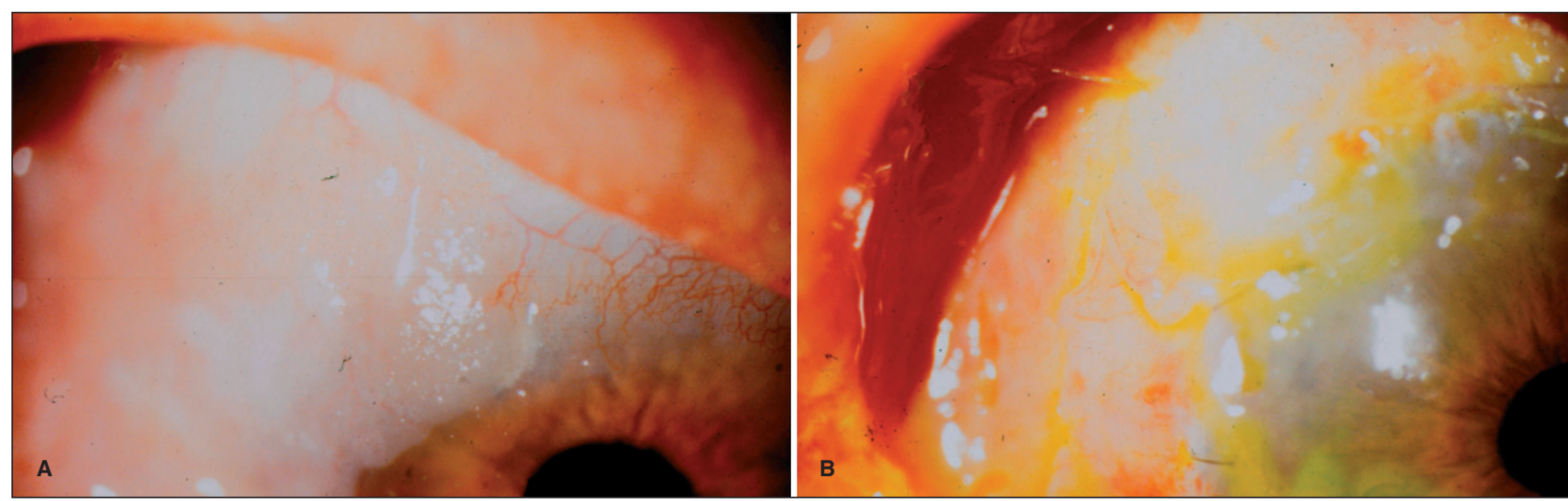

Figura 1 - A: Aspecto pré-operatório do caso no 1 evidenciando carcinoma de células escamosas conjuntival comprometendo região peri-límbica temporal superior; B: Aspecto pós-operatório (3 semanas) do caso no 1 demonstrando bom aspecto estético 


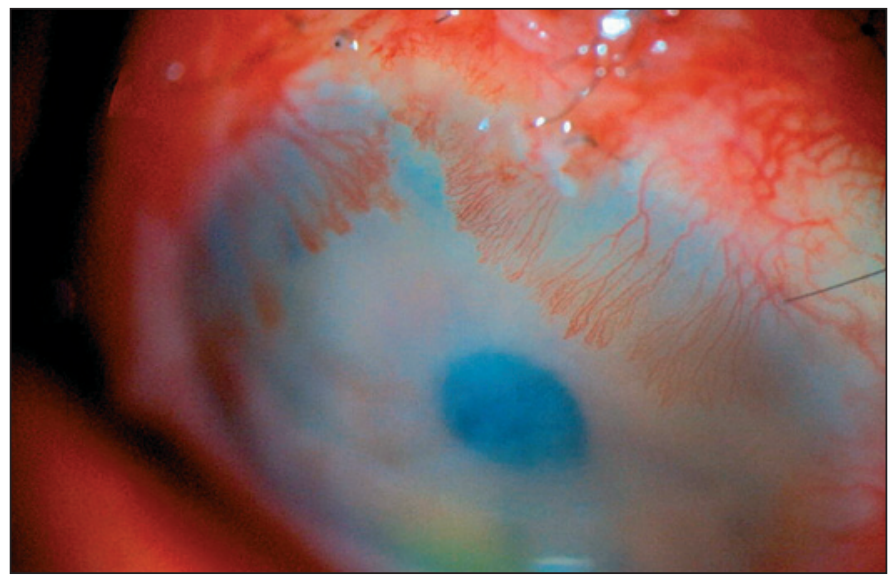

Figura 2 - Aspecto pós-operatório do caso nำ 4. Apresentou fibrose na região superior do globo ocular.

fibroblastos da córnea, limbo e conjuntiva em humanos ${ }^{(18)}$. Estudos em coelhos também demonstraram que a matriz estromal da membrana amniótica atrai neutrófilos, levando-os a apoptose. Além disso, a membrana amniótica contém vários inibidores de protease, tais como $\alpha 1$ antitripsina, $\alpha 2$ macroglobulina, inibidor da inter- $\alpha$ tripsina, inibidor da $\alpha 2$ plasmina e $\alpha 2$ antiquimiotripsina ${ }^{(19)}$. Todos esses estudos explicam porque a membrana amniótica ajuda a suprimir inflamação após excisão cirúrgica, fazendo desta um tecido substituto ideal para reconstrução em casos de extensa ressecção. A falta de inflamação e tecido cicatricial é particularmente importante quando ressecções extensas são feitas em associação com crioterapia, pois o aumento de inflamação pode comprometer a motilidade ocular ou causar simbléfaro.

As propriedades antiinflamatórias, antiangiogênicas e moduladoras da cicatrização da membrana amniótica puderam ser constatadas pelo bom aspecto clínico pós-operatório da maioria dos casos estudados, que apresentaram superfície córneo-conjuntival mais estável, sem erosões e com menos inflamação ou formação de cicatrizes ${ }^{(17,20-21)}$. Alguns autores mostraram resultados satisfatórios com a utilização de membrana amniótica como enxerto após remoção de tumores conjuntivais em 16 olhos $^{(3,16)}$.

Nos casos em que a região do limbo foi parcialmente comprometida pelo tumor ou mesmo pela ressecção cirúrgica com uma margem de segurança ampla, o transplante de membrana amniótica foi útil para tratar a deficiência límbica parcial, pois a membrana serve como substrato para expansão de epitélio corneal ${ }^{(20-22)}$. Já nos casos que apresentaram comprometimento total do limbo e foram submetidos a epiteliectomia total, foi importante que o transplante de membrana amniótica fosse associado ao transplante de limbo para que houvesse adequada recuperação da superfície corneal com epitélio normal. Nesses pacientes, as células límbicas do enxerto expandem-se no substrato amniótico, o que confere a necessidade de menor quantidade de células germinativas ${ }^{(11)}$. Os pacientes 1,3 e 4 , que foram submetidos a epiteliectomia total, receberam enxerto de limbo autólogo associado a membrana amniótica, sendo que os pacientes 1 e 3 recuperaram a superfície corneal, porém o paciente 4 desenvolveu deficiência límbica com neovascularização corneal $360^{\circ}$.

Recentemente, novas terapias no manejo das neoplasias conjuntivais têm sido publicadas, tais como mitomicina $\mathrm{C}$ tópica, interferon tópico e subconjuntival, 5-fluorouracil, além da ressecção tumoral com reconstrução da superfície ocular com membrana amniótica ${ }^{(16,23-26)}$. Este trabalho não buscou comparar essas técnicas, mas procurou mostrar que a membrana amniótica humana pode ser usada como enxerto alternativo importante, já que de sete pacientes submetidos ao tratamento cirúrgico com esse enxerto, $5(71,4 \%)$ obtiveram sucesso na reconstrução da superfície e $2(28,6 \%)$ obtiveram sucesso parcial.

\section{CONCLUSÃO}

Os resultados desse trabalho e as características da membrana amniótica leva-nos a sugerir ser esta uma boa opção para reconstrução da superfície ocular após remoção de tumores conjuntivais. Quando for realizada epiteliectomia total ou nos casos em que a área límbica remanescente for menor que $1 / 4$ do limbo, sugerimos que se realize transplante de limbo concomitante. Um número adicional de pacientes, associado a um período maior de seguimento é importante para conclusões adicionais.

\section{ABSTRACT}

Purpose: This study was designed to evaluate the use of human amniotic membrane for ocular surface reconstruction after conjunctival squamous cell carcinoma resection. Methods: Amniotic membrane was obtained at the time of cesarean section and was preserved at $-80^{\circ} \mathrm{C}$ in glycerol and cornea culture media at a ratio of $1: 1$. The inclusion criteria were patients presenting proliferating lesions suggestive of squamous cell carcinoma (flat or elevated white lesions resembling "fish meat") that involve the conjunctiva, limbus and cornea. Eight eyes of 8 patients with conjunctival "squamous cell carcinoma" underwent tumor resection with amniotic membrane transplantation. Three of these cases underwent total corneal epitheliectomy and amniotic membrane transplantation associated with limbal autograft. Results: Mean follow-up time was 17.8 months (range, 10-35 months). In four patients (71.4\%) surgical treatment was successful, with good ocular surface stability. In two patients $(28.6 \%)$ results were partially successful, with mild cicatricial alterations. One patient was excluded from the study due to aggressive tumor recurrence with intraocular invasion that needed to be removed with exenteration. Conclusion: This study suggests that amniotic membrane transplantation is a good alternative for ocular surface recons- 
truction after conjunctival squamous cell carcinoma resection.

Keywords: Conjunctival neoplasms/surgery; Carcinoma, squamous cell; Amnion/transplantation; Conjunctiva/transplantation

\section{REFERÊNCIAS}

1. Shields JA, Shields CL, De Potter P. Surgical management of conjunctival tumors. The 1994 Lynn B. McMahan Lecture. Arch Ophthalmol. 1997;115 (6):808-15. Review.

2. Cunha MC, Allemann N. Transplante autólogo de conjuntiva no tratamento de pterígio primário e recidivado. Arq Bras Oftalmol. 1993;56(1):78-81.

3. Tseng SC, Prabhasawat P, Lee SH. Amniotic membrane transplantation for conjunctival surface reconstruction. Am J Ophthalmol. 1997;124(6):765-74.

4. Tsubota K, Satake Y, Ohyama M, Toda I, Takano Y, Ono M, et al. Surgical reconstruction of the ocular surface in advanced ocular cicatricial pemphigoid and Stevens-Johnson syndrome. Am J Ophthalmol. 1996;122(1):38-52. Comment in: Am J Ophthalmol. 1996;122(6):914-5; Am J Ophthalmol. 1996;122(5):752-3.

5. Tseng SC, Prabhasawat P, Barton K, Gray T, Meller D. Amniotic membrane transplantation with or without limbal allografts for corneal surface reconstruction in patients with limbal stem cell deficiency. Arch Ophthalmol. 1998;116(4):431-41.

6. Shimazaki J, Yang HY, Tsubota K. Amniotic membrane transplantation for ocular surface reconstruction in patients with chemical and thermal burns. Ophthalmology. 1997;104(12):2068-76. Comment in: Ophthalmology. 2000; 107(3):411-2

7. Lee S, Tseng SC. Amniotic membrane transplantation for persistent epithelial defects with ulceration. Am J Ophthalmol. 1997;123(3):303-12.

8. Prabhasawat P, Barton K, Burkett G, Tseng SC. Comparison of conjunctival autografts, amniotic membrane grafts and primary closure for pterygium excision. Ophthalmology. 1997;104(6):974-85.

9. Gomes JA, Fernandes LHS, Komagome CM, Höfling-Lima AL, Prata Junior JA. Uso da membrana amniótica no tratamento de complicações póstrabeculectomia. Arq Bras Oftalmol. 2001;64(5):437-41.

10. Choi YS, Kim JY, Wee WR, Lee JH. Effect of the application of human amniotic membrane on rabbit corneal wound healing after excimer laser photorefractive keratectomy. Córnea. 1998;17(4):389-95.
11. Gomes JAP, Komagome CM, Santos N, Cunha MC, Freitas D. Membrana Amniótica nas cirurgias reconstrutivas da superfície ocular nas ceratoconjuntivites cicatriciais. Arq Bras Oftalmol. 1999;62(5):562-76.

12. Kim JC, Tseng SC. Transplantation of preserved human amniotic membrane for surface reconstruction in severely damaged rabbit corneas. Cornea. $1995 ; 14(5): 473-84$

13. Rosenbaum JM. Introduction of preserved human amniotic membrane. Miami, Biotissue standards; c1997.

14. Eye Bank Association of America. Medical Standards. Washington: EBAA, c1993.

15. Eye Bank Association of America. Procedures Manual. Washington: EBAA; c1992.

16. Espana EM, Prabhasawat P, Grueterich M, Solomon A, Tseng SC. Amniotic membrane transplantation for reconstruction after excision of large ocular surface neoplasias. Br J Ophthalmol. 2002;86(6):640-5. Comment in: Br J Ophthalmol. 2002;86(12):1460.

17. Tseng SC, Sun TT. Stem cells: ocular surface maintenance In: Brightbill FS, editor. Corneal surgery: theory, technique and tissue. $3^{\text {rd }}$ ed. St Louis: Mosby; c1999. p.9-18.

18. Lee SB, Li DQ, Tan DH, Meller DC, Tseng SC. Suppression of TGF-beta signaling in both normal conjunctival fibroblasts and pterygial body fibroblasts by amniotic membrane. Curr Eye Res. 2000;20(4):325-34.

19. Wang XF, Lin HY, Ng-Eaton E, Downward J, Lodish HF, Weinberg RA. Expression cloning and characterization of the TGF-beta type III receptor. Cell. 1991;67(4):797-805.

20. Anderson DF, Ellies P, Pires RT, Tseng SC. Amniotic membrane transplantation for partial limbal stem cell deficiency. Br J Ophthalmol. 2001;85 (5):567-75.

21. Tseng SC, Prabhasawat P, Barton K, Gray T, Meller D. Amniotic membrane transplantation with or without limbal allografts for corneal surface reconstruction in patients with limbal stem cell deficiency. Arch Ophthalmol. 1998; 116(4):431-41.

22. Gomes JA, Santos MS, Cunha MC, Mascaro VL, Barros JN, Sousa LB Amniotic membrane transplantation for partial and total limbal stem cell deficiency secondary to chemical burn. Ophthalmology. 2003;110(3):466-73.

23. Frucht-Pery J, Sugar J, Baum J, Stuphin JE, Pe'er J, Savir H, et al. Mitomycin $\mathrm{C}$ treatment for conjunctival-corneal intraepithelial neoplasia: a multicenter experience. Ophthalmology. 1997;104(12):2085-93.

24. Maskin SL. Regression of limbal epithelial dysplasia with topical interferon. Arch Ophthalmol. 1994;112(9):1145-6.

25. Vann RR, Karp CL. Perilesional and topical interferon alfa-2b for conjunctival and corneal neoplasia. Ophthalmology. 1999;106(1):91-7. Comment in: Ophthalmology. 1999;106(9):1642-3.

26. Yeatts RP, Engelbrecht NE, Curry CD, Ford JG, Walter KA. 5-Fluorouracil for the treatment of intraepithelial neoplasia of the conjunctiva and cornea. Ophthalmology. 2000;107(12):2190-5.

\title{
ABO Eletrônico
}

\section{A versão eletrônica dos Arquivos Brasileiros de Oftalmologia com textos completos está disponível em}

\author{
ABO - Arquivos Brasileiros de Oftalmologia \\ http://www.abonet.com.br
}

SciELO - Scientific Electronic Library Online http://www.scielo.org

Free Medical Journals

http://www.freemedicaljournals.com 